\title{
MRS plans joint 2022 MRS Spring Meeting events with societies in South Korea, Japan, and Singapore
}

\author{
By Lori A. Wilson and Gopal R. Rao
}

$\mathrm{T}$ he Materials Research Society (MRS) has strong connections with materials researchers across Asia, who form a significant portion of the MRS membership and meeting attendees. The MRS Spring Meeting has been held in Phoenix, Ariz., in recent years, but beginning in 2021, the MRS Spring Meeting enters an exciting new era of rotating venues. The 2021-2023 meetings are scheduled to be held in Seattle, Honolulu, and San Francisco, respectively. The Meeting in Honolulu, Hawai'i, presents an excellent opportunity for joint events with peer societies in Asia.

With this in mind, MRS is planning several collaborative events at the 2022 MRS Spring Meeting with materials societies from South Korea, Japan, and Singapore in an effort to share and discuss research across the Pacific Rim, provide networking opportunities across our communities, and grow a higher level of support and awareness for materials research and innovation.

Specifically, the 2022 MRS Spring Meeting will feature joint sessions and symposia with societies in South Korea, including the Korean Ceramic Society (KCS), The Korean Institute of Metals and Materials (KIM), MRS-Korea, and The Polymer Society of Korea (PSK). Joint symposia are also planned with The Japan Society of Applied Physics (JSAP), tentatively in the areas of complex states in biomimetic functionalities, carrier transport and doping in organic semiconductors, plasma processing for sustainability, and soft robotics. Additionally, MRS plans a joint symposium with MRS-Singapore at the 2022 MRS Spring Meeting.

"The joint symposia between MRS and the Korean materials societies are expected to offer exciting opportunities for researchers to get exposed to both new findings on fundamental materials science and its real-world industrial applications. I believe this collaboration will benefit both parties and be a great success," said Kisuk Kang, Seoul National University and MRS Board Director.

MRS has been working with these societies to finalize signed memorandums of understanding (MoUs), which emphasize the intent of collaboration

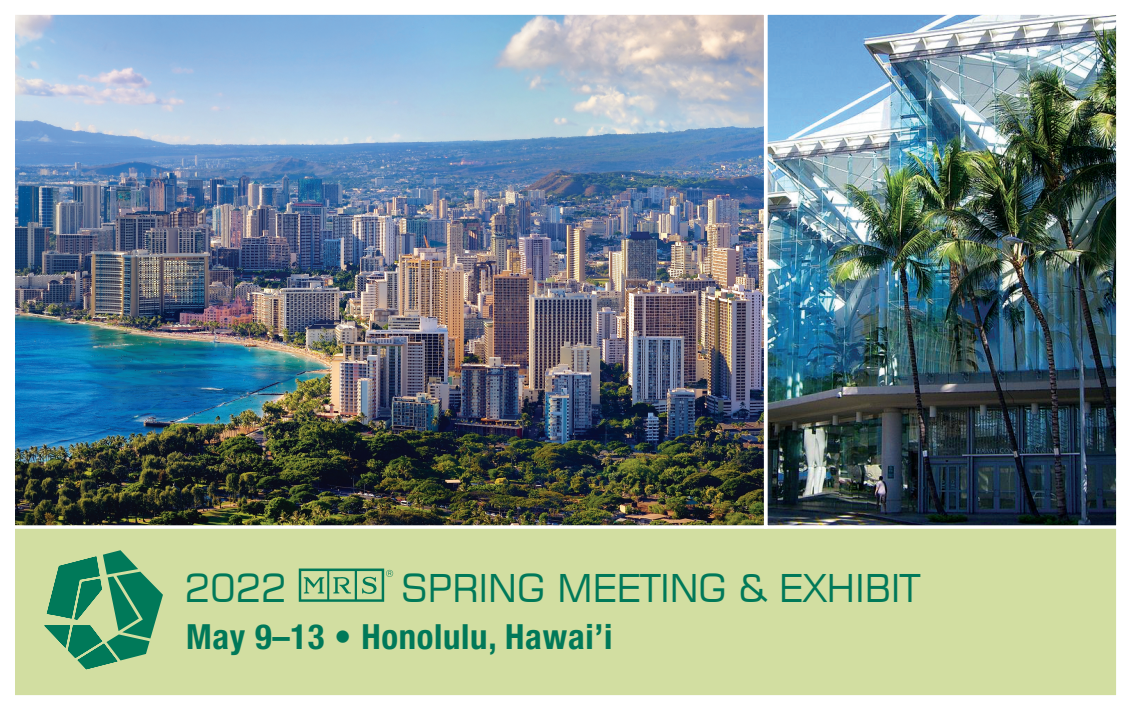

by promoting events and jointly hosting symposia and workshops. MoUs with JSAP and with MRS-Singapore have already been signed. MoUs with the Korean Societies will be signed in separate online ceremonies in late summer, with leaders from each of these societies as well as MRS participating. Videos of these signings will be available soon thereafter along with interviews with the principals.

"Following joint symposia at the MRS Spring Meeting in 2012, MRS and JSAP have had great success in organizing the 2013 JSAP-MRS Joint Symposia in Kyoto, with more than 1000 participants," said Takao Someya, The University of Tokyo. "Preparations for the 2022 joint symposia at the MRS Spring Meeting in Hawai'i are steadily in progress, and we anticipate further developments and exchanges between the two academic societies."

PSK is a representative academic society in Korea, with an eye toward advancing interdisciplinary research, science, and technology in polymerrelated chemistry, physics, biology, and engineering. The joint symposium at the 2022 MRS Spring Meeting will cover not only a technical session regarding "Polymers in Electronics: OPV, OLED, and Sensors," but may also feature student-organized events, as well as professional development and networking events for diverse international students and early-career members, said Junhan Cho, Dankook University.

PSK anticipates increased interactions with other materials-related Korean academic societies who will attend the Meeting, such as KIM and KCS. "The PSK also believes that this initiation will promote future collaboration in cutting-edge research on materials between Korea and other countries that 
can possibly be facilitated by organizing joint international conferences or international exchange programs for materials researchers," said Cho.

"KIM is excited to begin the first steps in initiating collaborations with MRS by organizing a joint symposium at the upcoming 2022 MRS Spring Meeting,' said Jeong Whan Han, president of KIM. "KIM values that MRS recognizes the importance in diverse representation in all meetings, and this joint symposium will encourage more representation from Korea to provide a platform for global interactions among materials scientists around the world.

Since KIM is traditionally known to be strong in the area of metals research, the joint symposium is planned to be on the topic of advanced structural materials at various length scales. "KIM will be promoting the joint symposium to all of its members, encouraging a successful symposium that can potentially lead to strong, prolonged future collaborations with MRS," said Han.

MRS-Korea will organize a session most likely on the topic of functional materials. "We will do our best to attract many participants to our joint symposium with MRS and to make the 2022 MRS Spring Meeting a successful one. We hope this collaboration will continue farther down the road," said Byungha Shin, KAIST, Republic of Korea.

MRS-Singapore and MRS collaborated on a joint symposium at the International Conference on Materials

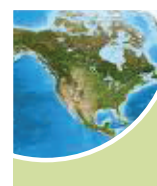

\section{Upcoming MRS/ASM joint events}

MRS is working with ASM International for joint events at the 2021 MRS Spring Meeting in Seattle and the 2022 MRS Spring Meeting in

Honolulu. A workshop on "STEM-in-SEM: From Basic Transmission Imaging to Rigorous Quantitative Analysis" is scheduled for the MRS 2021 Spring Meeting in Seattle in April. ASM International has proposed two workshops from their Electronic Device Failure Analysis Society (EDFAS) Meeting that will be co-located in Honolulu in 2022. Also, International Symposium for Testing and Failure Analysis (ISTFA) workshops will be co-located at this Meeting.

"The changing social and economic landscape has and will continue to impact the materials community and present unprecedented challenges," said Ryan Milosh of ASM International. "In responding to the challenges facing our community, ASM is excited to collaborate with MRS and bring technical content to MRS's Spring Meeting in 2022. The combination of ASM's unique content with MRS's already successful meeting should enhance the value to the attendees, exhibitors, members, volunteers, and the community as a whole. We look forward to working with MRS to find ways to benefit the materials community both now and into the future."

for Advanced Technologies (ICMAT) 2019 in Singapore, which is one of the premier activities of MRS-Singapore. "Encouraged by this success and the impact it has created in bringing both societies together for a better understanding of each other's mission, MRS and MRS-S are organizing two joint activities at the forthcoming ICMAT 2021 in Singapore," said B.V.R. Chowdari, ICMAT 2021 Chairman.

Building from this, MRS-Singapore members look to organize a joint symposium for the 2022 MRS Spring Meeting to further enable the collaboration between societies for the benefit of materials research communities worldwide.
Beyond these societies in Asia, the intent is to have a strong Pacific Rim connection at the 2022 Meeting in Hawai'i. Joint activities are also under discussion with the Sociedad Mexicana de Materiales (SMM) in Mexico and ASM International in the United States (see sidebar). "Hawai'i offers us a great opportunity to collaborate across the Pacific Rim to celebrate and promote materials research and innovation," said Todd $\mathrm{M}$. Osman, MRS Executive Director. "MRS is excited to continue working with our longtime friends at JSAP, SMM, MRSSingapore, and MRS-Korea and to establishing new relationships with PSK, KIM, KCS, and ASM International."

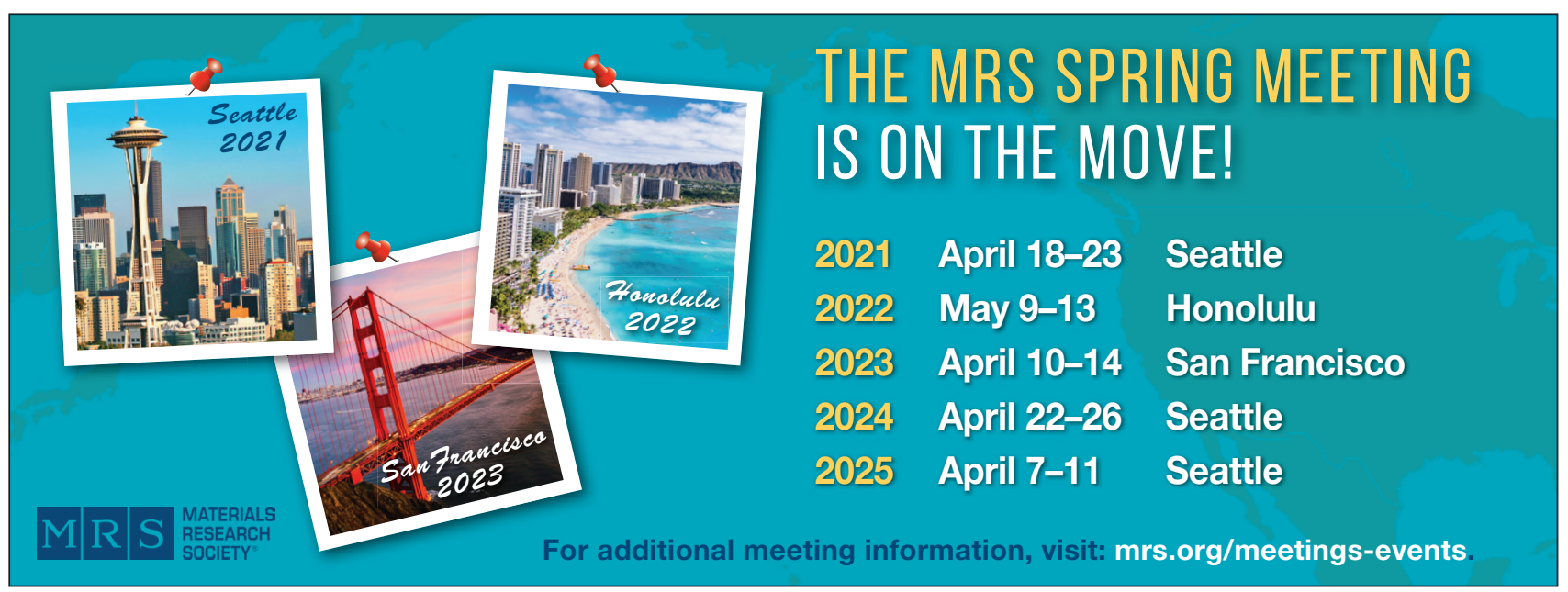

